\title{
Multiple Foreign Bodies in GIT in a Child Managed by Conservative Approach
}

\author{
Ahmed $\mathrm{M}^{1}$, Kumar $\mathrm{MM}^{2}$
}

\begin{abstract}
A seven years old child presented with multiple pebble stones in the gastro intestinal tract. Clinical examination did not reveal any abnormality except mild dehydration. Serial clinical examination for period of three days and regular radiographic follow up was done. Spontaneous expulsion of all the pebbles per rectum without any complication occurred in three days. In the absence of emergency surgical situation observation and watchful follow up of the patients will suffice the management.
\end{abstract}

Key words: Multiple foreign bodies in G.I.T, seeds, Animal bones, Mental retardation, Cell batteries.

\section{Introduction}

A ccidental ingestion of foreign bodies is commonly seen in children. Incidence of foreign body ingestion voluntarily due to a mental defect like conversion reaction is very rare. The nature of foreign bodies varies from buttons, pins, seeds, animal bones, metal objects and used cell batteries. Foreign bodies rarely produce complications unless they are obstructed at the narrow parts of the gastrointestinal tract. The sites where the foreign bodies are lodged commonly are crico-pharyngeal sphincter, pylorus and ileocaecal valve. If the foreign bodies do not produce any acute surgical emergency due to obstruction the patients usually do not need admission. Monitoring the patients with conservative serial clinical examination, follow up $\mathrm{X}$-rays will suffice as the foreign bodies pass out rectally within a few days.

\section{The Case}

A seven year old child presented with pain in the abdomen and difficulty in swallowing for two days, to the department of ENT, Government General Hospital, Kurnool, Andhra Pradesh, India. There was history of swallowing of pebbles as reported by the mother of the child. The mother of the patient was informed by the friends of the boy about the swallowing of pebbles by the child two days prior. The mother brought the child as she observed passing pebbles in the stools by the child. There was no history of vomiting. On examination the abdomen was soft, non-tender and there was no guarding or rigidity. The child was mildly dehydrated. There was no cyanosis or respiratory embarrassment. On ENT examination; Ear, Nose and
'Dr. S. Muneeruddin Ahmed, DLO, MS, Professor and Head of Department, ${ }^{2}$ Dr. M. Mahendra Kumar, MS (ENT) Assistant Professor. Both from the Department of ENT, Kurnool Medical College, Kurnool, Andhra Pradesh, India.

\author{
Address for correspondence: \\ Dr. M. Mahendra Kumar \\ E-mail: ahmedmunirent@gmail.com
}

\section{How to cite}

Ahmed M, Kumar MM. Multiple Foreign Bodies in GIT in a Child Managed by Conservative Approach. J Nepal Paediatr Soc 2015;35(1):67-69.

doi: http://dx.doi.org/10.3126/jnps.v35i1.10357

This work is licensed under a Creative Commons Attribution 3.0 License.

\section{(c) (i)}

throat were normal. Video laryngoscopy attempted and the larynx and hypopharynx were normal, except to minimal pooling of saliva in the pyriform fossae. The laryngeal crepitus was non-tender. Examination of the respiratory system was normal. A diagnosis of multiple radio opaque foreign bodies in the GIT was made after visualizing the radio opaque foreign bodies in the GIT. As there was history of difficulty in swallowing food was present in the child, upper end rigid oesophagoscopy was done under General Anaesthesia after correcting the dehydration. There was no foreign body seen in the oesophagus, the oesophagoscope was passed up to the cardiac end. As there were no further signs of acute abdomen, the child was kept under observation with serial clinical examination 
and serial X-ray of the abdomen and pelvis to note the progress of the foreign bodies. The initial X-rays of the neck, chest and abdomen and pelvis revealed multiple radio opaque shadows of pebbles in the stomach, intestine and colon. Blood examination revealed the Haemoglobin to be $6 \mathrm{gm} \%$. Follow up X-rays of the abdomen showed the progression of the stones into the colon and piling of stones into the rectum. The child passed all the pebbles per rectum over a period of three days from the date of admission. The child complained of sacral pain and was unable to walk straight during these three days. The child was discharged on the $4^{\text {th }}$ day after a final radiographic picture. The child was discharged with prescription of haematinics to correct anaemia.

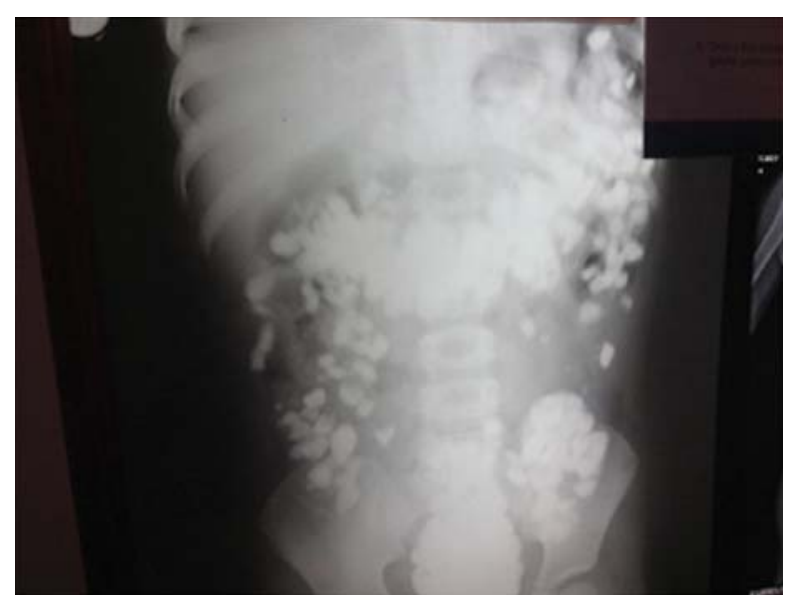

Fig 1: X-ray KUB region showing Multiple radio opaque shadows

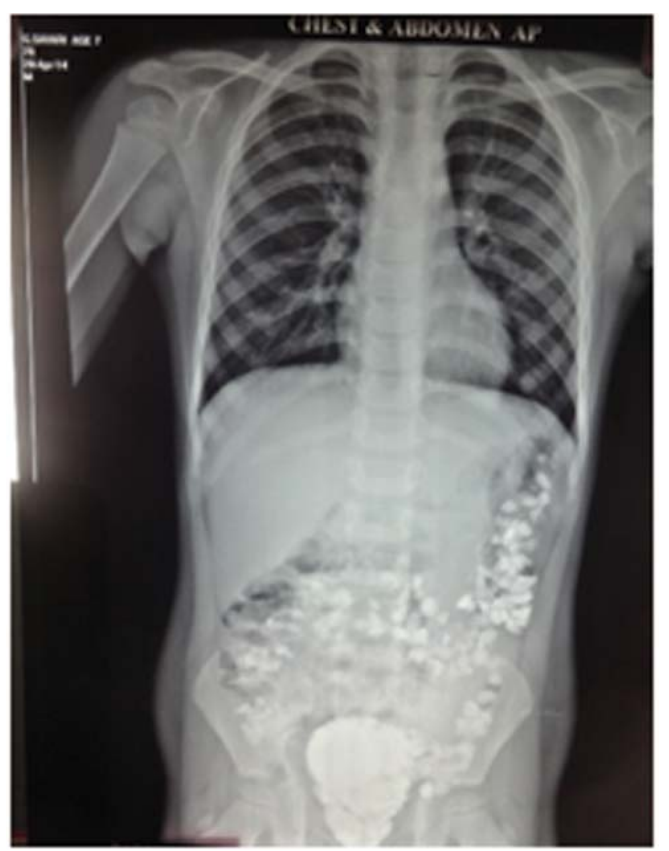

Fig 2: X-ray showing multiple radio opaque shadows in the colon and rectum

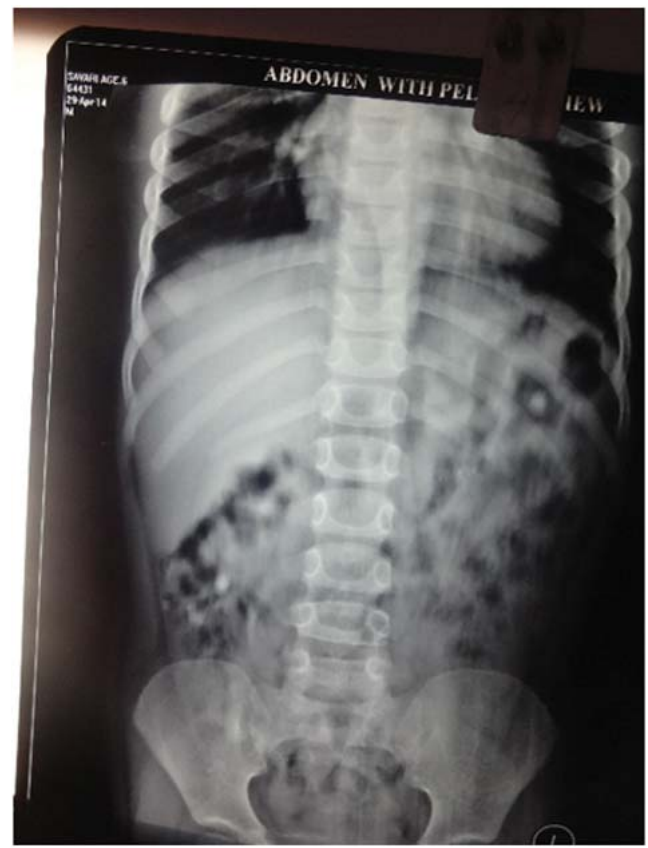

Fig 3: X-ray showing complete evacuation of the bowel except two radio opaque objects which passed out later.

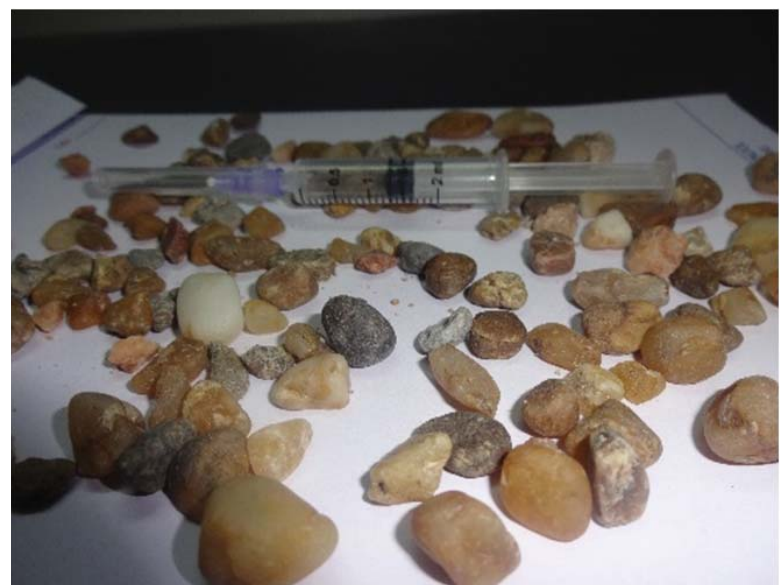

Fig 4: Total number of stones passed spontaneously per rectum

\section{Discussion}

Children presenting with foreign bodies in the GIT is a common scene in the OPD of any ENT department. Ingestion of foreign body (FB) is usually accidental. It occurs commonly between 6 months to 9 years of age. Majority (70\%) of the instances the F.B. passes off spontaneously ${ }^{1}$. 10 to $20 \%$ of patients need endoscopic removal and less than $1 \%$ requires surgical intervention ${ }^{2}$. In the United States, coins are the most common foreign bodies ingested by children ${ }^{2}$. Ingestion of multiple foreign objects and repeated episodes are uncommon occurrences and usually occur in children with developmental delay ${ }^{2}$. Symptoms are often related to the site of the F.B. Feeling of something preventing to swallow, at the neck or middle of the chest 
suggests location of F.B may be in the upper or lower oesophagus, respectively ${ }^{3,4}$. If there is sub-sternal pain then it is more likely due to mucosal ulceration of the oesophagus, which can be demonstrated while doing endoscopy. It may be due to presence of F.B. for more than 72 hours. In India history of an attempt to remove the F.B. by manipulating with fingers in the throat is seen in more than $90 \%$ of patients, which results in oedema of the supra-glottic mucosa or lacerations of pharyngeal walls and uvula. Patients of all ages may present with refusal of feeds or dysphagia, drooling, or respiratory symptoms including wheezing, stridor, or choking.

Approach to management: a thorough history taking and clinical examination always helps in diagnosing an oesophageal foreign body and to the prevention of its complications. Examination of the respiratorysystem, observing for stridor, breathlessness, presence of swelling in the neck, crepitus or erythema suggests oesophageal perforation necessitating surgical intervention. X-rays taken in biplanes usually confirms the findings and to localize the site of the foreign body. Plastic or wooden toys and few fish bones may not readily be seen on plain films; observing for indirect evidence of the radiolucent foreign body (such as an air-fluid level in the oesophagus) may be helpful. If the plain radiograph does not reveal any foreign body or abnormalities, management depends on the characteristics of the patient's clinical status and the suspected foreign body. When the presence of other foreign bodies is suspected, although one is observed on plain films, computed abdominal tomography can be considered as a proper alternative ${ }^{1}$. CT scan can also be undertaken when there is suspected ingestion of cell batteries also ${ }^{5}$.

In most of the instances children with oesophageal foreign bodies are brought by their parents because the ingestion was seen or reported to them, in these settings, they often are asymptomatic. Intestinal foreign body cases resulting from foreign body ingestion accidentally or due to a conversive reaction are seen less frequently in adulthood when compared to childhood. While treating the intestinal foreign body patients, importance should be given to the location of the FB, its shape, and whether it is a sharp one or not before deciding, whether an out-patient treatment or surgical intervention is required. Although sharp objects pass through gastrointestinal tract without difficulty in $90 \%$ of the cases, they may also be removed using fibre optic gastroscopy without waiting ${ }^{6}$. Early endoscopic intervention, in general, may be required and applied for objects wider than $2 \mathrm{~cm}$ and longer than $6 \mathrm{~cm}$, since their passage through pylorus and duodenum will become difficult. Once these foreign bodies pass beyond pylorus and ileocaecal valve, they easily pass out of the lumen per rectum spontaneously. Losanof et al operated all cases since the foreign bodies have pointed and sharp edges ${ }^{1,7}$. Our patient was managed conservatively and monitored as an inpatient. The mother was informed about the probable progress of his condition and suggested that the child to be admitted for observation; She should inform as soon as possible in case of acute abdominal pain and/or any other complaints.

\section{Conclusion}

In conclusion watchful management in multiple foreign bodies of the GIT resulted in successful elimination of all the pebbles in a child who had ingested them voluntarily due to conversion reaction, relieving anxiety of the mother, who had to be convinced again and again about the outcome.

\section{References}

1. Mehmet Eryilmaz, Ozkun Ozturk, oner mentes; Intracolonic multiple pebbles in young adults: radiographic imaging and conventional approach to a case; World J Gastroenterol 2006;12(37):607476.

2. Mark A Gilger, MD; Ajay K Jain, MD; Mark E Mc Omber, MD; Foreign bodies of the oesophagus and gastrointestinal tract in children.UpToDate ${ }^{\circledR}$ online journal, http://www.uptodate.com/home/ wolters-kluwer-health-clinical-solutions.

3. Athanassiadi K, Gerazounis M, Metaxas E, Kalantzi N. Management of esophageal foreign bodies: a retrospective review of 400 cases. Eur J Cardiothorac Surg 2002; 21:653.

4. Reilly S, Carr L. Foreign body ingestion in children with severe developmental disabilities: a case study. Dysphagia 2001;16:68.

5. Elie Alam, Marc Mourad, Samir Akel, and Usamah Hadi, A Case of Battery Ingestion in a Pediatric Patient: What Is Its Importance? Case Reports in Pediatrics, Volume 2015, Article, ID 345050, 3 pages http://dx.doi.org/10.1155/2015/345050.

6. Webb WA. Management of foreign bodies of the upper gastrointestinal tract: update. Gastrointest Endosc 1995;41:39.

7. Sharieff GQ, Brousseau TJ, Bradshaw JA, Shad JA. Acute esophageal coin ingestions: is immediate removal necessary? Pediatr Radiol 2003;33:859. 